\title{
Headache Attributed to Obsessive Compulsive Disorder of Mastication
}

\author{
Mianwang He, Xiaolin Wang and Shengyuan $\mathrm{Yu}^{*}$ \\ Department of Neurology, Chinese PLA General Hospital, China
}

*Corresponding authors: Shengyuan Yu, Department of Neurology, International headache center, General Hospital, Chinese PLA, Fuxing Road 28, Haidian District, 100853 Beijing, China, Tel: 8610-55499118, E-mail: yusy1963@126.com

Mastication is an effective coping behavior for anxiety, likely due to activity of the hypothalamic-pituitary-adrenal axis and autonomic nervous system can be attenuated by mastication [1]. Some studies showed that chewing gum was associated with lower levels of perceived stress, such as anxiety and depression [2,3]. An experiment in rats found that chewing may activate the dopaminergic system in the ventral hippocampus to suppress stress-induced anxiogenic behavior [4]. But hyperactivity of musculi masticari can be the cause of headache $[5,6]$. Headaches caused by bruxism were first reported by Monica WS in 1959 [7]. Later chronic headache attributed to bruxism [8] and headache attributed to hypertrophied temporal muscles $[9,10]$ were reported. Here we present a unique case.
A 51-years-old man who had developed severe phobia, anxiety since took illicit drugs twice 10 years ago, subsequently palpitation and shortness of breath appeared, having a continuous feeling that someone would attack him and he would die soon. Only mastication can partially relieve phobia and anxiety, and continuous involuntary mastication habit with left side teeth was developed. Anxiety and depression diagnosis was made by local clinic, but he didn't take the prescribed drugs. About half year later he developed dragging and tight pain in left temporal area. The pain's verbal rating scale (VRS) was 3 , and no treatment was received. 2 years later, his headache was aggravated and unbearable, VRS was 6 , could be aggravated by mastication, had to stop masticating sometimes, even speak

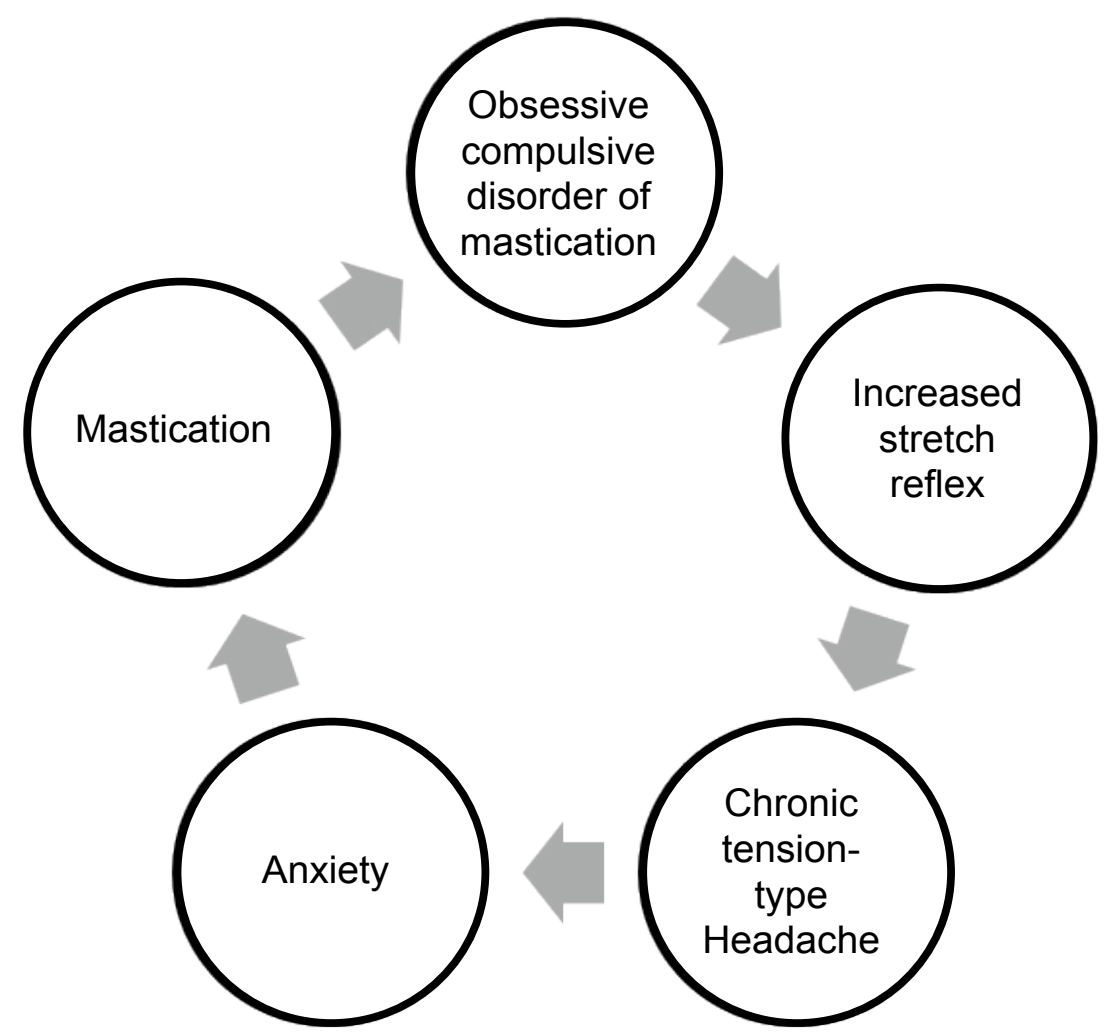

Figure 1: Possible underlying mechanism of chronic headache attributed to obsessive compulsive disorder of mastication.

Citation: Mianwang H, Wang X, Shengyuan Y (2016) Headache Attributed to Obsessive Compulsive Disorder of Mastication. Int J Brain Disord Treat 2:017 
was seriously influenced. He started to take drugs mirtazapine, clonazepam, duloxetine prescribed by local neurologists, in about 2 months, his anxiety and phobia symptom were partially relieved. However, his left temporal headache and mastication habit persisted, numerous treatments had failed and daily life ability was severely impaired. This year he was admitted to our neurology ward. No focal neurologic sign was revealed by neurologic examination. Brain magnetic resonance imaging scan was normal. Temporalmandibular joint X-ray was normal. The initial diagnosis was chronic tension-type headache, so amitriptyline $25 \mathrm{mg} 1$ time per night, eperisone $50 \mathrm{mg} 3$ times per day, and pregabalin $75 \mathrm{mg} 2$ times per day was given, but no headache relieve was achieved in two weeks, and left temporal muscle blockade with lidocaine $0.1 \mathrm{~g}$ and dexamethasone $5 \mathrm{mg}$ failed either. Later we noticed his headache was accompanied by repetitive mastication habit of left teeth, so obsessive compulsive disorder of mastication was considered. Oxcarbazepine $0.3 \mathrm{~g} 3$ times/ day was given, then involuntary repetitive mastication activity was reduced, and his headache symptom was gradually improved in one week. Headache VRS reduced to 1 to 2 . He continued to take the drugs, and headache symptoms and repetitive mastication habit gradually disappeared in 2 months follow-up.

Our case is a unique case which demonstrate that obsessive compulsive disorder of mastication was a cause of persist chronic headache, and other study also found association between anxiety and bruxism, resulting in facial pain and headache [11]. Temporalmandibular joint disorder was excluded by normal temporalmandibular joint X-ray in our case. We inferred that obsessive compulsive disorder of mastication was initiated by anxiety in our case. Some studies had suggested that Oxcarbazepine [12] and Carbamazepine [13] were effective in the treatment of obsessive compulsive disorder, the good response in our case further verified this view. Otherwise amplitude of the stretch reflexes recorded in the temporalis and masseter muscles was higher in chronic tension type headache patients than control was also reported [14]. We inferred that stretch reflex of musculi masticari was increased by obsessive compulsive disorder of mastication, which was initiated by anxiety , might indicating underlying mechanism of chronic tension-type headache in this case. Chronic headache could make anxiety even worse. The whole proposed process was illustrated by figure 1 .
In conclusion, our study found that obsessive compulsive disorder of mastication initiated by anxiety was a cause of chronic tension-type headache, and increased stretch reflex of musculi masticari might be the underlying mechanism.

\section{Authors' contributions}

SY guided the study and revised the manuscript. MH conceived and drafted the manuscript. ZD and XW did the literature review.

\section{References}

1. Elenkov IJ, Wilder RL, Chrousos GP, Vizi ES (2000) The sympathetic nervean integrative interface between two supersystems: the brain and the immune system. Pharmacol Rev 52: 595-638.

2. Smith $A$ (2013) Effects of chewing gum on stress and health: a replication and investigation of dose-response. Stress Health $29: 172-174$.

3. Smith AP, Chaplin K, Wadsworth E (2012) Chewing gum, occupational stress, work performance and wellbeing. An intervention study. Appetite 58: 1083-1086.

4. Ono Y, Koizumi S, Onozuka M (2015) Chewing prevents stress-induced hippocampal LTD formation and anxiety-related behaviors: a possible role of the dopaminergic system. Biomed Res Int 10.

5. Ericsson SG, Riise C (1970) Headache (6): muscular hyperactivity in the chewing apparatus. Lakartidningen 67: 4983-4988.

6. Lous I, Olesen J (1982) Evaluation of pericranial tenderness and oral function in patients with common migraine, muscle contraction headache and 'combination headache'. Pain 12: 385-393.

7. Monica WS (1959) Headaches caused by bruxism. Ann Otol Rhinol Laryngol 68: 1159-1162.

8. Berlin R, Dessner L (1960) Bruxism and chronic headache. Lancet 2: 289-291.

9. Jimenez-Jimenez FJ, Zurdo-Hernandez JM, Orti-Pareja M, Puertas-Munoz I (2003) Headache induced by chewing in a female patient with hypertrophied temporal muscles. Rev Neurol 37: 198.

10. Vordenbaumen S, Groiss SJ, Dihne M (2009) Isolated unilateral temporal muscle hypertrophy: a rare cause of hemicranial headache. Headache 49: 779-782.

11. Alves AC, Alchieri JC, Barbosa GA (2013) Bruxism. Masticatory implications and anxiety. Acta Odontol Latinoam 26: 15-22.

12. McMeekin $\mathrm{H}$ (2002) Successful treatment of obsessive compulsive disorder with oxcarbazepine. A case report. J S C Med Assoc 98: 316-320.

13. Greve KW, Adams D (2002) Treatment of features of Obsessive-Compulsive Personality Disorder using carbamazepine. Psychiatry Clin Neurosci 56: 207-208.

14. Peddireddy A, Wang K, Svensson P, Arendt-Nielsen L (2009) Stretch reflex and pressure pain thresholds in chronic tension-type headache patients and healthy controls. Cephalalgia 29: 556-565. 